\title{
TRADIÇÕES E CONTRADIÇÕES DA PÓS-GRADUAÇÃO NO BRASIL
}

\author{
Cássio Miranda dos Santos*
}

A experiência brasileira de pós-graduação nos últimos anos é a coisa mais positiva da história da educação superior no Brasil e é também a que tem que ser levada a sério.

(Darcy Ribeiro)

\begin{abstract}
RESUMO: O presente artigo discute o modelo brasileiro de pós-graduação. Dentre vários aspectos são enfocados o caráter dependente dos cursos de mestrado no tocante à produção científica e a forte influência do modelo norte-americano de pós-graduação na estruturação do modelo brasileiro. É tratada também a problemática da incompatibilidade dos títulos pós-graduados conseguidos no Brasil e em instituições estrangeiras, assim como a questão do rigor dos mestrados acadêmicos brasileiros cujas exigências são compatíveis com doutorados de outros países.
\end{abstract}

Palavras-chave: Pós-graduação. Mestrado. Doutorado. Dissertação.

\section{Traditions AND CONTRADICTIONS IN THE BRAZILIAN POSTGRADUATE STUDIES}

ABSTRACT: The present essay discusses the Brazilian model of Masters Degree. Among several aspects, it focuses both on its dependence on scientific production and on the strong influence of the North American model on the structure of the Brazilian one. It then approaches the problem of incompatibility between the postgraduate degrees obtained in Brazil and in foreign institutions, and the issue of the rigidity of the Brazilian academic masters whose requirements are compatible with those of Doctor Degrees of some countries.

Key words: Masters degree. Postgraduate studies. Doctor Degree. Thesis.

Mestre e doutor em educação pela UNESP/Marília e professor de Didática e Filosofia da Educação no UNI-BH. E-mail: cassiom@acad.unibh.br

Educ. Soc., Campinas, vol. 24, n. 83, p. 627-641, agosto 2003 

tou sua avaliação positiva com relação à política de implantação e desenvolvimento dos cursos de pós-graduação no Brasil. Tal processo deve, contudo, ser analisado em suas diversas facetas. A faceta da possibilidade de desenvolvimento científico e tecnológico (provavelmente a observada por Darcy Ribeiro), a faceta da possibilidade de continuidade da carreira acadêmica, a faceta da abertura de uma nova possibilidade de capacitação profissional (docente ou não). A faceta da dependência de modelos externos, contudo, própria do contexto de sua implantação, deve ser também considerada, uma vez que trouxe implicações na estrutura dos currículos, programas, nas formas de avaliação e em diversas outras áreas dos cursos de pós-graduação, cuja análise se torna necessária para uma eventual correção de rota.

Os primeiros passos da pós-graduação no Brasil foram dados no início da década de 1930, na proposta do Estatuto das Universidades Brasileiras, onde Francisco Campos propunha a implantação de uma pós-graduação nos moldes europeus. Tal modelo foi implementado tanto no curso de Direito da Universidade do Rio de Janeiro quanto na Faculdade Nacional de Filosofia e na Universidade de São Paulo.

Na década de 1940 foi pela primeira vez utilizado formalmente o termo "pós-graduação" no Artigo 71 do Estatuto da Universidade do Brasil. Na década de 1950 começaram a ser firmados acordos entre Estados Unidos e Brasil que implicavam uma série de convênios entre escolas e universidades norte-americanas e brasileiras por meio do intercâmbio de estudantes, pesquisadores e professores.

O grande impulso para os cursos de pós-graduação do Brasil só se deu na década de 1960. Já no início da década houve uma iniciativa importante na Universidade do Brasil na área de Ciências Físicas e Biológicas (seguindo o modelo das graduate schools norteamericanas), resultado de um convênio com a Fundação Ford, e outra na mesma universidade, na área de Engenharia, com a criação da Comissão Coordenadora dos Programas de Pós-Graduação em Engenharia (COPPE).

É também do começo da década a implantação do mestrado em Matemática da Universidade de Brasília, o doutorado do Instituto de Matemática Pura e Aplicada, o mestrado e doutorado na Escola Superior de Agricultura de Viçosa, na Universidade Federal Rural do Rio de Janeiro, assim como os cursos de pós-graduação no ITA e na UnB. 
As duas tendências mais fortes que marcaram a pós-graduação brasileira foram a européia, (principalmente na USP) e a norte-americana (ITA, Universidade Federal de Viçosa e Universidade Federal do Rio de Janeiro), sendo esta última a que as principais marcas deixou.

A modernização do Brasil nos anos de 1960 deu-se dentro de um contexto de integração entre países periféricos e países centrais. Essa integração implicava a expansão de mercados consumidores nos países periféricos e o fomento dos centros produtores de Ciência \& Tecnologia (países centrais). O objetivo das nações mais desenvolvidas era o aumento de mercados consumidores e o desestímulo à concorrência científica ou tecnológica.

Foi neste contexto de dependência em relação às nações centrais que se deu a instalação da pós-graduação no Brasil. Uma sociedade dependente vincula-se a outra, supostamente mais organizada e desenvolvida, para estabelecer uma relação de "parceria subordinada". Tal dependência, contudo, é extremamente nociva mormente na área da pesquisa, uma vez que a compra de know-how estrangeiro se torna um mau negócio por desestimular as iniciativas de desenvolvimento tecnológico do país importador, limitando a formação de cientistas e pesquisadores. Nesse contexto, o valor do cientista depende do impacto internacional que seu trabalho tem e da consonância do tema de sua pesquisa com os interesses dos países desenvolvidos. A interferência da United States Agency for International Development (USAID) nos rumos da educação brasileira na década de 1960 deve ser entendida sob esta ótica (Romanelli, 1993, p. 196; Werebe, 1994, p. 173).

A importação de teóricos e de teorias, esta "ciência de reprodução”, só foi implantada em razão da visão de modernização da intelectualidade orgânica da elite, que consistia em tentar reproduzir no Brasil marcas dos países "adiantados", principalmente os EUA, no intuito de tornar o país subdesenvolvido o mais parecido com o país desenvolvido. Segundo Cunha, “a modernização da universidade objetiva nessa perspectiva (re)produzir aqui a ciência 'internacional', a ser ensinada segundo padrôes de idêntica categoria, sem veleidades autonomistas" (Cunha, 1983, p. 255).

Em 1965, com o Parecer 977 do Conselho Federal de Educação, dá-se a implantação formal dos cursos de pós-graduação no Brasil. Segundo Newton Sucupira, o modelo de pós-graduação a ser implantado era adequado à nova concepção de universidade, oriundo dos países mais desenvolvidos. 
O Parecer 977 estabelecia a pós-graduação conforme o modelo norte-americano. A pós-graduação stricto sensu dar-se-ia em dois níveis independentes e sem relação de pré-requisitos entre o primeiro e o segundo (mestrado e doutorado). A primeira parte dos cursos seria destinada a aulas e a segunda à confecção do trabalho científico de conclusão (dissertação ou tese). Os currículos seriam compostos conforme o modelo norte-americano, que compreendia o major (área de concentração) e o minor (matérias conexas).

Um breve olhar sobre a história da implantação da pós-graduação no Brasil revela, pois, suas tradiçốes e indica uma série de contradiçōes. Dentre estas podem ser destacadas a questão da dependência científico-cultural, o problema da incompatibilidade dos títulos e a questão do rigor dos mestrados acadêmicos.

\section{A questão da dependência científico-cultural}

Um primeiro aspecto importante identificado no estudo da história da pós-graduação no Brasil refere-se à forte influência norte-americana na implantação dos primeiros cursos, influência essa que se deu principalmente na sua estrutura, ficando os critérios de avaliação mais próximos dos modelos europeus não-anglo-saxões.

No início da década de 1980, o professor Ernst Hamburger fez uma crítica à estrutura da pós-graduação brasileira, propondo que os cursos no Brasil desenvolvessem "linhas de pesquisa de maior interesse para o país, libertando-se, na medida do possível, dos modismos e preconceitos internacionais" e definissem "programas e currículos partindo da realidade e das aspirações brasileiras e não somente da tradição em outros países" (Hamburger, 1980, p. 90). Tal ênfase, porém, quando adotada, acabou por gerar problemas em termos de repercussão internacional dos cursos, uma vez que dificultou a publicação de trabalhos no exterior, por serem os temas tão próprios e por vezes específicos da realidade brasileira, o que já não é tão comum nos trabalhos de Ciências Biológicas e Exatas.

Ao criticar o critério da avaliação das publicações dos programas de pós-graduação brasileiros, Zancan afirmou que nas áreas de ciências humanas houve

uma preocupação de todos os comitês com os veículos de divulgação da produção docente, notadamente ainda de nível mais local do que nacional e/ou internacional. (...) Na realidade o sistema de avaliação implantado não per- 
mite aquilatar a expressão da subárea do conhecimento no contexto mundial, já que não há indicadores universais que sirvam de referência para todas as áreas de conhecimento. (Zancan, 1997)

A internacionalização das publicações é um padrão totalmente adequado aos trabalhos nas áreas de Ciências Exatas e Biológicas, cujos temas não estão, necessariamente, circunscritos a um espaço geográfico, cultural e histórico. A publicação em periódicos internacionais de trabalhos na área de Ciências Humanas é algo muito mais difícil e improvável. Como tornar viável a publicação internacional de um trabalho sobre os índios caiapós ou sobre o movimento dos sem-terra no Pontal do Paranapanema? Há, efetivamente, interesse das editoras estrangeiras por esses temas?

As normas das revistas internacionais foram estabelecidas nos países desenvolvidos e traduzem as necessidades desses países, e somente destes. Os trabalhos realizados no Brasil seguindo estas normas estarão mais ligados às sociedades desenvolvidas do que a sua própria comunidade. (Hamburger, 1980, p. 86)

A dependência cultural faz com que as atividades científicas desenvolvidas no país estejam impregnadas por mecanismos e propósitos que condicionam o comportamento de seus pesquisadores. Um desses mecanismos é a

atribuição de prestígio acadêmico aos cientistas em função da quantidade de artigos de sua autoria publicados em revistas de renome internacional, constituindo-se esse mecanismo na melhor medida de qualidade do que o país dispõe. Portanto, tais artigos, por estarem ligados a equipes editoriais em atividade nos países desenvolvidos, devem refletir problemas de interesses desses países, para que sejam publicados. (Nunes, 1978, p. 38)

Mammana também critica a excessiva preocupação com a produção científica voltada ao mercado externo. Tal política é prejudicial pois "em vez de avaliar o grau de utilidade do cientista para o país, mede, de certa maneira, o grau de ressonância em que esse cientista está com os problemas da moda, e, portanto, o quanto ele é útil para os países desenvolvidos" (Mammana, 1976, p. 6). Muitas vezes o próprio currículo dos cursos de pós-graduação revela a relação de dependência ao tentar

reproduzir conhecimentos importados e defasados da realidade do país dependente, muitas das vezes não considerando problemas que já foram solucionados nos países desenvolvidos, e que já fazem parte do domínio indus- 
trial, e portanto de seu patrimônio econômico, mas cujo conhecimento é crucial para os países dependentes ou periféricos. (Nunes, 1978, p. 39)

Uma severa crítica que é feita ao modelo brasileiro de pós-graduação seria, pois, essa sua dependência cultural. Segundo Ernst Hamburger, "a regulamentação da pós-graduação no Brasil foi copiada até nos mínimos detalhes da norte-americana” (Hamburger, 1980, p. 84). Góes, em 1972, fez grandes elogios à decisão de se adotar o modelo norte-americano de pós-graduação no Brasil, afirmando que este era "sem dúvida, no mundo desenvolvido, o que alcançou os mais elevados padrōes e deu os melhores frutos em termos quantitativos e qualitativos" (Góes, 1972, p. 226). O próprio relator do Parecer 977/ 65, Newton Sucupira, admitiu tal opção; um dos capítulos chega a ter o sugestivo título: "Um exemplo de pós-graduação: a norte-americana". Ao longo do referido capítulo, e por todo o Parecer, o relator argumenta em favor da implantação do modelo norte-americano de pós-graduação no Brasil. São abundantes termos em língua inglesa como: master, doctor, college, graduate school, undergraduate, qualifying, scholarship, major, acreditation.

Fazendo a ressalva de que o modelo norte-americano devia servir de orientação e não de matriz para uma eventual cópia, Newton Sucupira afirmou que "sendo, ainda, incipiente a nossa experiência em matéria de pós-graduação, teremos de recorrer inevitavelmente a modelos estrangeiros para criar nosso próprio sistema”. A preferência pela sistemática norte-americana justificava-se, segundo o relator, pelo êxito de sua longa existência e pela influência sobre a pós-graduação de outros países:

Vale assinalar que na Inglaterra, recentemente, o já famoso Robbins Report, que estudou as condições de expansão e aperfeiçoamento do ensino superior britânico, não hesitou em recomendar às universidades britânicas o uso de certas técnicas e processos da pós-graduação norte-americana. (Brasil, Parecer $977 / 65)$

Outro fator que contribuiu para esta opção pelo modelo norte-americano foi a tradição dos Estados Unidos em cursos de pós-graduação (graduate). Um aspecto interessante nessa importação de modelo se refere à própria terminologia. Nos Estados Unidos o ensino de graduação recebe o tratamento de undergraduate, ao passo que a pós-graduação é conhecida como graduate. É de se avaliar se tais denominaçôes não revelam também a natureza e os propósitos dos cursos, cabendo à pós-graduação norte-americana 
o papel de formação que no Brasil é devido aos cursos de graduação. Já em meados do século XIX havia cursos em algumas universidades norte-americanas e no ano de 1876 foi implantado definitivamente um programa de pós-graduação na Universidade John Hopkins.

Diversos autores têm criticado a importação de modelos de ensino, principalmente relativos à pós-graduação. No mesmo artigo em que elogiava a adoção do modelo norte-americano de pós-graduação, Góes ressaltou, contudo, que "é difícil precisar em que medida a organização e os procedimentos administrativos norte-americanos podem ser adotados integralmente em nosso meio, dadas as diferenças existentes entre a nossa estrutura universitária e a daquele país" (Góes, 1972, p. 226).

A tomada da pós-graduação norte-americana como padrão seria interessante se fosse encarada como um processo de fertilização, adaptado às condições e ao contexto nacionais. A transplantação de um modelo, ao contrário, revela mimetismo. "Nesse campo, ainda menos que em outros, a imitação acrítica e a incorporação de modelos estrangeiros podem ter conseqüências inesperadas e funestas se não levarmos, adequadamente, em conta as tradições universitárias nacionais" (Graciarema, 1972, p. 271).

Uma evidência da norte-americanização da pós-graduação brasileira estava no privilégio dado, segundo Sarmento, para a "cátedra e a formação intelectual das elites, garantindo a preservação da estrutura de classe. A estrutura da universidade americana, controlada pela comunidade, valorizando a utilidade prática do conhecimento" (Sarmento, 1986, p. 39). Embora formalmente a cátedra tenha sido substituída pelo departamento na reformulação do sistema universitário brasileiro, aquela continuou existindo de fato. A constatação do valor dado à utilidade prática do conhecimento revela o paradoxo do padrão da pós-graduação de origem com o academicismo dos mestrados brasileiros, diferença essa que tende a ser minimizada com o advento do mestrado profissional.

Não obstante a clara opção pelo modelo norte-americano de pós-graduação, percebe-se na estrutura dos mestrados brasileiros uma série de problemas devidos à adoção de aspectos e particularidades de modelos de outros países. Pode-se afirmar que a pós-graduação brasileira é híbrida, e por isso tem algumas disfunções. Segundo Graciarema, "é fácil notar superposições e incongruências derivadas da presença simultânea e não integrada dessas duas dife- 
rentes tradiçôes" (Graciarema, 1972, p. 269). Foram adotadas a estrutura dos cursos norte-americanos e a forma de avaliação dos europeus, a alta exigência dos mestrados europeus (não-anglo-saxões) e o baixo prestígio dos mestrados norte-americanos.

\section{O problema da incompatibilidade dos títulos}

Os termos referentes à pós-graduação empregados no Brasil não encontram, necessariamente, correlatos em outros países. $\mathrm{Na}$ tradição espanhola, após o bacharelato vem a licenciatura; já no Brasil, a licenciatura é um curso no nível de graduação, não de pósgraduação. Na tradição anglo-saxônica, após o bachelor segue-se o master; nesse sistema o bachelor "é um tipo de estudo que, se fosse terminal, seria um pouco mais que decorativo (...). Uma das funções mais importantes do mestrado anglo-saxão foi a de especializar e aprofundar a formação dispersa e multidisciplinar do bachelor" (idem, ibid., p. 268). Por outro lado, na França o título de docteur de specialité equivale ao título de mestre no Brasil. Já nos Estados Unidos, o master como grau final não é muito valorizado, conta "apenas como um começo de carreira, e é um grau de obtenção relativamente fácil, com um nível de exigências consideravelmente mais baixo que o doutorado" (idem, ibid., p. 271).

A incompatibilidade entre títulos de pós-graduação expedidos pelas universidades brasileiras e estrangeiras é tamanha que a USP não aceita como equivalentes a mestrado e doutorado (para fins de revalidação) diversos títulos obtidos na França, tais como: licence, maîtrise, Diplôme d'Études Approfondies (DEA) e Diplôme d'Études Supérieures Spécialisées (DESS) (com a ressalva de que os títulos de doctorat de $3^{\text {ime }}$ cycle, docteur igénieur e doctorat d'université seriam aceitos na categoria de mestrados). Pode-se afirmar que os títulos de doctorat e docteur não aceitos pela USP sejam obtidos em programas sem a devida qualidade ou em estruturas curriculares e exigências acadêmicas incompatíveis com os padrōes nacionais de doutorado. Segundo Giraud,

com a reforma de 1984, completada em 1988, passa a existir na França somente um tipo de diploma de doutorado, que é obtido após a defesa de uma tese, em média oito anos depois do início dos estudos universitários. Sua duração, sua natureza, seu nível são semelhantes aos do $\mathrm{Ph}$.D. norte-americano ou aos do doutorado dos grandes países europeus. (Giraud, 1996, p. 5) 
A citação de Giraud faz uma referência ao nivelamento "Ph.D. - Doutor", que no Brasil encontra muita resistência, sobretudo nos meios não-acadêmicos, nos quais o título de doutor em filosofia (Ph.D. - Philosophy Doctor) goza de um prestígio social muito superior ao de doutor em outra área de conhecimento. O título de Ph.D. tem sua origem na Faculdade de Filosofia do modelo universitário alemão, pelo qual a antiga Faculdade de Artes se tornou Faculdade de Filosofia (que em parte serviu de "inspiração" para a criação da USP em 1934 e, posteriormente, das Faculdades de Filosofia, Ciências e Letras que proliferaram no Brasil na década de 1960, sem que tivessem, em sua maioria, um curso de Filosofia propriamente dito). Na Alemanha, então, o concludente de um doutorado em qualquer área das ciências ou das letras passou a fazer jus ao título de doutor em filosofia; os doutorados em Ciências Naturais ou Exatas, ao título de doctor rerum naturalium e em Ciências Sociais e Econômicas, doctor rerum politicarum (Brasil, Parecer 977/65).

Em 1965, quando da instituição da pós-graduação brasileira, os títulos franceses equivalentes ao Ph.D. norte-americano e alemão seriam os de docteur ès sciences e docteur ès lettres, que corresponderiam aos doutorados ligados aos cursos da área de Ciências Humanas (Brasil, Parecer 977/65). Eco confirma a equiparação desses títulos:

Via de regra, porém, a tese propriamente dita é reservada a uma espécie de supraformatura, o doutorado, procurado só por aqueles que desejam aperfeiçoar-se e especializar-se como pesquisadores científicos. Esse tipo de doutorado possui vários nomes, mas doravante vamos referir-nos a ele com uma sigla anglo-saxônica de uso quase internacional, Ph.D. (que significa Philosophy Doctor, doutor em filosofia, embora designe qualquer espécie de doutor em Ciências Humanas, do sociólogo ao professor de grego; nas matérias não-humanistas usam-se outras siglas, como por exemplo medicine doctor). (Eco, 1983, p. 2) (Grifo nosso)

A valorização do Ph.D. tem, contudo, respaldo no próprio $\mathrm{Pa}$ recer 977/65. Segundo Newton Sucupira, valendo-se novamente do modelo norte-americano, o doutorado em Filosofia (Ph.D.) distingue-se dos demais por se tratar de um "doutorado de pesquisa", ao passo que os doutorados em Ciências Médicas, Engenharia, Educação e outros seriam “doutorados profissionais". No Parecer, Sucupira admitia a possibilidade da adoção do título Ph.D. para os doutora- 
dos de pesquisa brasileiros, porém desaconselhava tal medida por considerar que tal título não teria a devida ressonância em nosso ambiente universitário.

Na USP, em 1999, também não eram aceitos para revalidação os

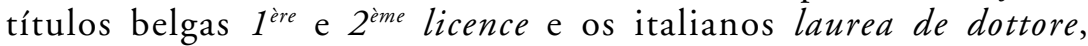
baccalareatum e specializzazione (ou perfezionamento), este último somente sendo aceito mediante seu reconhecimento oficial pelo ministério italiano da Púbblica Instruzione, ao considerá-lo equivalente ao título de dottore di ricerca. As limitaçóes estabelecidas pela USP, assim como por diversas outras universidades do país, explicam-se como precaução e reação à problemática xenofilia que ainda existe dentro de diversos setores do meio acadêmico. $\mathrm{O}$ deslumbramento com tudo o que é "estrangeiro" leva muitos a estabelecerem como objetivo de vida a realização de um curso de pós-graduação no exterior, sem que muitas vezes se atentem para as qualificaçôes da instituição para onde se dirigem e conseqüentemente para o valor do título que obterão. A globalização é um fenômeno que ultrapassa o campo econômico e atinge outros setores, inclusive a educação. Embora uma hipotética "unificação" de títulos seja inviável, é razoável pensar em se estabelecerem mundialmente padrōes mínimos de qualidade para a identificação de instituiçóes idôneas que se caracterizem pela excelência. Logo, os diplomas terão, também, uma valorização diferenciada. $\mathrm{Na}$ maioria das vezes é muito mais seguro cursar o mestrado ou doutorado em uma boa universidade brasileira que fazê-lo em uma estrangeira, de questionável reputação. Segundo Darcy Ribeiro:

$\mathrm{Na}$ concepção norte-americana, inglesa, o mestrado em si é uma prova de alfabetização. A maior parte dos universitários formados nas universidades são uns analfabetos, no sentido de que não dominam a língua, são incapazes de escrever um texto limpo e correto. $\mathrm{O}$ mestrado tem a finalidade de saber se um jovem que se formou é capaz de escrever articuladamente, numa linguagem limpa. Examina-se até a gramática da pessoa para saber se os erros de ortografia não são demasiados. Se ele é capaz de tomar informaçôes sobre um tema e redigir de maneira legível sobre o assunto, dentro de um nível acadêmico, ele demonstra que é um letrado, não um analfabeto. (Ribeiro, 1980, p. 75)

Os mestrados brasileiros têm um problema de identidade que vem desde sua criação. O próprio autor do Parecer 977/65 reconhecia o baixo prestígio acadêmico que os mestrados tinham tanto na Europa quanto nos Estados Unidos e, não obstante, aconselhou a sua instalação no país. 
Em Oxford e Cambridge o grau de Mestre das Artes é concedido sem qualquer exame a todo aquele que haja obtido o grau de Bacharel (...). Nas universidades escocesas o M.A. é o grau concedido ao término do curso de graduação. Nos Estados Unidos, por força da influência inglesa permaneceu o grau de Mestre, sendo, por muito tempo, conferido sem maiores exigências no fim da graduação, como era o caso do chamado "Master's Degree in cursu". (Brasil, Parecer 977/65)

Sucupira segue em sua análise crítica do título de mestre nos Estados Unidos afirmando que, mesmo no século $\mathrm{XX}$, depois de alterada a situação anterior, o grau de mestre seria útil na maioria das vezes como sinal de competência profissional. "É importante igualmente para o magistério secundário, sobretudo porque em muitos estados o mestrado é garantia de melhor remuneração. No ensino superior é de menor valia, pois o Ph.D. é título necessário para o acesso na carreira de professor universitário" (Brasil, Parecer 977/65).

O Brasil tem se mostrado um terreno fértil para a proliferação e pulverização de títulos. O período conhecido como República Velha (1889-1930) foi dominado por "coronéis" que nunca cursaram uma Academia Militar; em pleno século XXI os graduados em Medicina ou Direito são considerados “doutores", sem terem, a grande maioria, voltado à universidade após a conclusão da residência médica ou do bacharelado. O tratamento de "doutor" dado aos bacharéis em Direito não é uma exclusividade brasileira; sua origem remonta às universidades do final da Idade Média, quando "chamavam-se mestres todos os licenciados que faziam parte da corporação dos professores em todas as faculdades, com exceção da Faculdade de Direito onde os professores se intitulavam doutores" (Brasil, Parecer 977/65) (grifo nosso).

\section{$\mathrm{O}$ rigor dos mestrados acadêmicos}

No Brasil, os critérios de avaliação dos alunos dos mestrados têm um rigor muito semelhante ao da avaliação dos doutorados. Adalberto Vasquez, diretor de Avaliação da CAPES em 1998, reconheceu que os programas de mestrado eram por demais rígidos e que tal rigidez era considerada pelas agências um dos fatores quer levavam à evasão ( $O$ Estado de S. Paulo, 14/8/1998, A9). Da mesma forma entende Therezinha Oliveira ao afirmar que "na atualidade, seria ingênuo pensar que os alunos do mestrado não são capazes de produzir teses. A realidade está aí comprovando o contrário" (Oliveira, 1997, p. 4). 
Em 1972, Graciarema levantava que um dos fortes argumentos para o alto nível de exigência dos mestrados era o de que, "enquanto não houve possibilidades na América Latina para estabelecer pós-graduações completas que incluíssem o doutorado, a única coisa possível e aconselhável seria fazer bons mestrados" (Graciarema, 1972, p. 270).

A própria CAPES reconhece que um dos aspectos problemáticos da pós-graduação brasileira seria o superdimensionamento do papel dos mestrados, muitas vezes organizados como verdadeiros pequenos doutorados, "como uma consequiência natural do fato de o mestrado ter sido inicialmente o principal foco das políticas governamentais, de ter-se constituído no nível mais elevado de formação oferecido em algumas áreas" (Brasil, CAPES, 1996).

Therezinha Oliveira, durante encontro de pós-graduação da UFMG, relatou que, em mais de duas décadas trabalhando com cursos de pós-graduação, teve contato com teses de ótima qualidade em cursos de mestrado: "Sou testemunha disso na pós-graduação da Medicina na UFMG, onde por 20 anos como professora de Metodologia de Pesquisa acompanhei e orientei pesquisas e a própria escritura de teses de excelência reconhecida nacional e internacionalmente" (Oliveira, 1997, p. 4).

Rosseti também apontou o rigor e o alto nível de exigência dos mestrados nacionais: "O problema é que, com o desenvolvimento da pós-graduação no país, o mestrado adquiriu várias conformações. Em algumas áreas - como a médica -, tornou-se um verdadeiro doutorado" (Rosseti, 1997).

O mestrado brasileiro vive uma grande ambigüidade desde a sua instituição em 1965, pois adotou o modelo norte-americano para a estrutura, mas não adotou o mesmo modelo em termos de exigências. Nos dizeres de Sucupira, "no caso do Ph.D. a exigência da tese é universal, enquanto ao M.A. ora se requer uma dissertação, memória ou ensaio, ora se consideram suficientes os exames prestados" (Brasil, Parecer 977/65). Possivelmente por esta razão, Fátima Bayma de Oliveira afirma que os mestrados brasileiros mantêm "os alunos a eles atrelados por um tempo médio elevado, levando em alguns casos o dobro do tempo dos mestrados americanos e, ao final, poucos são os alunos que obtêm o título de mestre" (Oliveira, 1995, p. 138).

Ernst Hamburger também critica a ambigüidade da pós-graduação brasileira ao afirmar que 
mesmo nos EUA as complicadas regras da pós-graduação estão sendo aos poucos abandonadas, atendendo aos reclamos de professores e alunos. Entretanto a regulamentação implantada aqui mantém todas as regras de lá, e com o agravante de uma tradição educacional muito mais burocrática, seguindo a letra dos regulamentos com maior rigidez do que lá. (Hamburger, 1980, p. 84)

A adoção de uma estrutura norte-americana de pós-graduação não teve seu correlato nos critérios de avaliação e promoção. Conforme já mencionado anteriormente, as exigências dos mestrados brasileiros têm semelhanças com os seus análogos europeus (nãoanglo-saxões), não com os norte-americanos. O rigor da comunidade acadêmica, sobretudo na área de Educação, tem sido extremado, adotando uma postura muito mais conservadora que o próprio texto da lei. Percebe-se que, ao passo que em várias áreas foram aceitas outras modalidades de trabalho final de curso, conforme a orientação do Parecer 977/65, na área de Educação tem sido exigida "a elaboração de dissertações ambiciosas, em alguns casos, segundo o modelo das pesquisas recomendadas nos programas de doutorado" (Oliveira, 1995, p. 162). São as contradições do modelo brasileiro de pós-graduação.

Recebido em outubro de 2002 e aprovado em fevereiro de 2003.

\section{Referências bibliográficas}

BRASIL. Conselho Federal de Educação. Parecer no 977/65. Definição dos cursos de pós-graduação. Brasília, DF, 1965.

BRASIL. Ministério da Educação e Cultura. Plano Nacional de Pósgraduação no Brasil. Brasília, DF, 1975.

BRASIL. Coordenação de Aperfeiçoamento de Pessoal de Nível Superior. Reformulação do Sistema de Avaliação da Pós-graduação: o modelo a ser implantado na avaliação de 1998 (documento em discussão). Brasília, DF: CAPES, 1996.

BRAVO, L. A pós-graduação no Brasil. Revista Brasileira de Estudos Pedagógicos, Brasília, DF, v. 58, n. 128, p. 388-397, 1972.

CAPES tenta reduzir índices de evasão de cursos. O Estado de S. Paulo, São Paulo, A9, 14 ago. 1998. 
CARDOSO, F.H.; FALETTO, E. Dependência e desenvolvimento na América Latina. 4. ed. Rio de Janeiro: Zahar, 1977. 114p.

CHAGAS FILHO, C. Atualidades e perspectivas da pós-graduação. Revista Brasileira de Estudos Pedagógicos, Brasília, DF, v. 58, n. 128, p. 241-248, 1972.

COELHO, E.C. Sinecura acadêmica. São Paulo: Vértice, 1985.

CUNHA, L.A. A pós-graduação no Brasil: função técnica e função social. Revista de Administração de Empresas, São Paulo, v. 14, n. 5, p. 66-70, 1974.

CUNHA, L.A. A expansão do ensino superior: causas e conseqüências. Debate \& Crítica, São Paulo, n. 5, p. 27-58, 1975.

CUNHA, L.A. A universidade critica. Rio de Janeiro: Francisco Alves, 1983. 260p.

DREIFUSS, R.A. 1964: a conquista do Estado. Petrópolis: Vozes, 1981. $815 \mathrm{p}$

ECO, U. Como se faz uma tese. São Paulo: Perspectiva, 1983.

FÁVERO, M.L.A. (Coord.). Faculdade Nacional de Filosofia. Rio de Janeiro: UFRJ, 1989.

GÓES, P. Aspectos administrativos da educação pós-graduada no Brasil. Revista Brasileira de Estudos Pedagógicos, Brasília, DF, v. 58, n. 128, p. 224-231, 1972.

GIRAUD, J. Organização dos estudos de doutorado na França. São Paulo: NUPES, 1996.

GRACIAREMA, J. Pós-Graduação em ciências sociais na América Latina. Revista Brasileira de Estudos Pedagógicos, Brasília, DF, v. 58, n. 128, p. 265-280, 1972.

GUIRAlDELli JR., P. História da educação. São Paulo: Cortez, 1991. 240p.

HAMBURGER, E. Para que pós-graduação? Encontros com a civilização brasileira, Rio de Janeiro: Civilização Brasileira, 1980.

LEITE, C.B. A pós-graduação e o papel da Capes. Revista Brasileira de Estudos Pedagógicos, Brasília, DF, v. 58, n. 128, p. 352-358, 1972. 
MAMMANA, C.Z. O grande equívoco do almejado prestígio científico. Dados \& Idéias, São Paulo, v. 1 n. 5, p. 4-8, 1976.

MENDES, D.T. Pesquisa e ensino no mestrado de educação. Revista Brasileira de Estudos Pedagógicos, Brasília, DF, v. 58, n. 128, p. 249264, 1972.

NUNES, L.C.P. Análise da política de pós-graduą̧ão no Brasil. 1978. Dissertação (Mestrado) - Faculdade de Educação, Universidade Federal do Rio de Janeiro, Rio de Janeiro.

OLIVEIRA, F.B. Pós-graduação: educação e mercado de trabalho. São Paulo: Papirus, 1995. 202p.

OLIVEIRA, T.F.R. Dissertação e teses na pós-graduação: diferenças. Belo Horizonte: UfMG, 1997. (mimeo)

RIBEIRO, D. Os cursos de pós-graduação. Encontros com a Civilização Brasileira, Rio de Janeiro: Civilização Brasileira, 1980.

ROMANELLI, O.O. História da educação no Brasil. 15a ed. Petrópolis: Vozes, 1993.

ROSA, L.P. Universidade, intelectuais e ciência para transformação social existem? In: $O$ PODER e o saber: universidade em debate. Rio de Janeiro: Marco Zero, 1984.

ROSSETI, F. Existência do mestrado é questionada. Folha de S. Paulo, São Paulo, 21 nov. 1997.

SANTOS, C.M. A proletarização do trabalho docente: entre o mito, a realidade e a possibilidade. Trabalho \& Educação, Belo Horizonte, n. 4, ago./dez. 1998.

SARMENTO, D.C. Cursos de pós-graduação em educação: influência sobre a percepção de seus egressos quanto a problemas educacionais brasileiros. 1986. Tese (Doutorado) - Faculdade de Educação, Universidade Federal do Rio de Janeiro, Rio de Janeiro.

WEREBE, M.J.G. 30 anos depois: grandezas e misérias do ensino no Brasil. São Paulo: Ática, 1994. 304p.

ZANCAN, G. Análise da avaliação da Capes. Jornal da Ciência, Rio de Janeiro, v. 11, n. 360, maio 1997. 